Published in final edited form as:

J Acad Nutr Diet. 2015 April ; 115(4): 511-518. doi:10.1016/j.jand.2014.12.011.

\title{
Weighing everyday matters: Daily weighing improves weight loss and adoption of weight control behaviors
}

\author{
Dori M Steinberg, PhD, RD ${ }^{1,2}$, Gary G Bennett, $\mathrm{PhD}^{1,3}$, Sandy Askew, $\mathbf{M P H}^{1}$, and Deborah F \\ Tate, PhD $^{2}$ \\ ${ }^{1}$ Duke Obesity Prevention Program, Duke Global Health Institute, Duke University, Durham, \\ North Carolina \\ ${ }^{2}$ Department of Nutrition, University of North Carolina at Chapel Hill, Chapel Hill, North Carolina \\ ${ }^{3}$ Department of Psychology and Neuroscience, Duke University, Durham, North Carolina
}

\section{Abstract}

Background-Daily weighing is emerging as the recommended self-weighing frequency for weight loss. This is likely because it improves adoption of weight control behaviors.

Objective-Examine whether weighing everyday is associated with greater adoption of weight control behaviors compared to less frequent weighing.

Design-Longitudinal analysis of a previously conducted 6-month randomized-controlled trial.

Participants/setting-Overweight men and women in Chapel Hill, NC in the Intervention arm $(\mathrm{N}=47)$.

\begin{abstract}
Intervention-The intervention focused on daily weighing for weight loss using an e-scale that transmitted weights to a study website, along with weekly e-mailed lessons and tailored feedback on daily weighing adherence and weight loss progress.
\end{abstract}

Main outcome measures-We gathered objective data on self-weighing frequency from escales. At baseline and 6 months, weight change was measured in clinic, and weight control behaviors (total items $=37$ ), dietary strategies, and caloric expenditure from physical activity were assessed via questionnaires. Caloric intake was assessed using an online 24-hour recall tool.

Statistical analyses-We used chi-square tests to examine variation in discrete weight control behaviors and linear regression models to examine differences in weight, dietary strategies, and calorie intake and expenditure by self weighing frequency.

(C) 2014 by the Academy of Nutrition and Dietetics. All rights reserved.

Corresponding Author: Dori M. Steinberg, PhD, RD, Duke Obesity Prevention Program, Duke Global Health Institute: Room 134, Trent Hall, 310 Trent Drive, Box \#90519, Durham, NC 27708; P: 919-613-5453; F: 919-681-7748; Dori M. Steinberg: dori.steinberg@duke.edu.

Publisher's Disclaimer: This is a PDF file of an unedited manuscript that has been accepted for publication. As a service to our customers we are providing this early version of the manuscript. The manuscript will undergo copyediting, typesetting, and review of the resulting proof before it is published in its final citable form. Please note that during the production process errors may be discovered which could affect the content, and all legal disclaimers that apply to the journal pertain. 
Results-Fifty-one percent of participants weighed everyday ( $n=24)$ over 6 months. The average self-weighing frequency among those weighing less than daily $(n=23)$ was $5.4 \pm 1.2$ days per week. Daily weighers lost significantly more weight compared to those weighing less than daily (mean difference, $-6.1 \mathrm{~kg} ; 95 \% \mathrm{CI}-10.2,-2.1 ; \mathrm{p}=.004$ ). The total number of weight control behaviors adopted was greater among daily weighers ( $17.6 \pm 7.6$ vs. $11.2 \pm 6.4 ; \mathrm{p}=.004)$. There were no differences by self-weighing frequency in dietary strategies, caloric intake, or caloric expenditure.

Conclusions-Weighing everyday led to greater adoption of weight control behaviors and produced greater weight loss compared to weighing most days of the week. This further indicates daily weighing as an effective weight loss tool.

\section{Keywords}

Obesity; Weight Loss; Self-monitoring; Daily weighing; Dietary change

\section{Introduction}

Obesity affects more than one-third of Americans ${ }^{1}$ and is associated with an increased risk for many chronic diseases ${ }^{2}$ and some cancers. ${ }^{3}$ The new guidelines for the management of overweight and obesity in adults released from the American College of Cardiology (ACC), American Heart Association (AHA), and The Obesity Society indicate that even a 3\% weight loss among over weight and obese individuals can improve risk factors for these chronic diseases. ${ }^{4}$ Thus, finding ways to produce even small amounts of weight loss can be clinically meaningful. The most successful weight loss treatments include elements of selfmonitoring as a means to increase self-awareness about how behaviors impact weight. ${ }^{5,6}$ This is supported by self-regulation theory, which posits that individuals are better able to self-regulate behaviors when they self-monitor and evaluate current behavior compared to goals. ${ }^{7}$ This then reinforces current behavior or allows for self-correction. One such selfmonitoring strategy is daily self-weighing. Compared to less frequent weighing, daily selfweighing may allow for better self-regulation of body weight as small changes in body weight can be identified on a daily basis and changes in diet and exercise behaviors initiated as a result. ${ }^{8}$ Although there is emerging evidence that daily weighing can promote greater weight loss compared to less frequent weighing, ${ }^{9-12}$ the mechanisms are unclear. Given that daily self-weighing does not impact weight loss directly, but rather via diet and physical activity behaviors that result in caloric deficits, it is important to better understand the behavior changes prompted by daily weighing.

Few studies have examined associations between daily weighing and discrete weight control behaviors. Results suggest that more frequent weighing is associated with greater adoption of diet and exercise behaviors that may promote weight loss. ${ }^{13,14}$ These studies, however, were conducted cross-sectionally and did not specifically assess whether daily weighing within the context of a behavioral weight loss intervention leads to greater engagement in weight control behaviors compared to less frequent weighing. It is less clear whether daily weighing will trigger uptake of diet and exercise behaviors that promote weight loss, in that it prompts these behavioral changes rather than it happening concurrently. As such, it is 
important to examine whether there is greater adoption of behaviors known to be associated with weight loss among individuals who are instructed to daily weigh.

We recently conducted WEIGH, a 6-month randomized controlled trial assessing the efficacy of weight loss intervention focusing on daily weighing as compared to a delayed intervention control group. ${ }^{9}$ Participants were instructed to weigh daily using network connected e-scales and were provided with tailored feedback and skills training via weekly emails. Using the e-scales we were able to capture an objective measure of self-weighing frequency. We also measured various diet, exercise, and behavioral outcomes associated with weight loss success. As such, this study provides a unique opportunity to assess the relationship between daily weighing and weight control behaviors, along with nuanced differences in weight loss by self-weighing frequency. We hypothesized, based on selfregulation theory, that daily weighing would lead to greater adoption of weight control behaviors as compared to less frequent weighing.

\section{Methods}

\section{Study Design}

As previously stated, we present a secondary analysis from the WEIGH study. A detailed description of the study design, intervention and report of the main outcomes has been previously published. ${ }^{9}$ Briefly, eligibility criteria included adults aged $18-60$ years, body mass index (BMI) of 25-40, Internet access, and no medical conditions that might affect participation. Participants were recruited predominantly from the Chapel Hill, NC area. Following eligibility screening, informed consent was obtained and baseline measures were collected. Participants ( $\mathrm{N}=91$ ) were then randomized to a 6-month daily self-weighing intervention $(n=47)$ or a delayed intervention control group $(n=44)$. All participants were reassessed at 3 and 6 months. Data collection occurred from February to August 2011 in Chapel Hill, North Carolina. The University of North Carolina at Chapel Hill institutional review board approved and monitored the study.

\section{Intervention Description}

Intervention participants were instructed to weigh themselves daily and were provided with network-connected e-scales. The e-scale uses the wireless cellular network to transmit weight data. Weights were then automatically transferred to a website that displayed individualized graphs of weight change over time. Participants were able to $\log$ on to the website and view these graphs. Participant data on self-weighing frequency and weight change were also displayed in a separate researcher interface. These data informed an algorithm that was used to provide tailored feedback on self-weighing frequency and weight loss to each participant via weekly e-mails. The e-mails also included behavioral weightcontrol lessons based on topics from gold standard weight loss trials and other Internetbased trials that were adapted for the WEIGH study. ${ }^{15-17}$ These lessons provided information on evidence-based strategies for weight loss, along with mini exercises for selfreflection and problem solving. The delayed control group received no intervention during the study period and was blinded to the focus on daily weighing. They received a modified version of the intervention after the 6-month study period was complete. We did not collect 
any data other than weight from the control group after they received the delayed intervention. As such, the current analysis is focused on participants in the intervention group.

\section{Measures}

Demographics-At baseline, a variety of demographic variables were collected to help characterize the sample including age, sex, race/ethnicity (American Indian/Alaskan Native; Asian; Black or African-American; Hispanic, Latino, Portuguese, or Cape Verdean; White; Other), and education [Grade School (6 years or less); Junior High school (7-9 years); High School (10-12 years); Vocational Training (beyond High School); Some College (less than 4 years); College/University degree; Graduate or Professional Education].

Anthropometric-At baseline and 6 months, blinded evaluation staff collected height at baseline using a wall-mounted stadiometer, and weight using a calibrated and standardized digital scale at the UNC Weight Research Program clinic. Percent of body weight lost and absolute weight loss were calculated from baseline to 6 months.

Self-weighing frequency-Self-weighing frequency was measured objectively throughout the intervention using the e-scales. E-scale data included the weight measurement and the date and time of day of weighing. The maximum number of persondays for e-scale measurement totaled 168 days, equivalent to 24 weeks of intervention. The total number of days weighed was calculated for each participant. Average number of days weighed per week was calculated by dividing the total number of days weighed by 24 . For participants with multiple weights on each day, we marked it as one day of weighing. To better assess differential outcomes among those who weighed daily versus less often, we created two categories: participants with an average weighing frequency $=7$ days per week $(\mathrm{n}=24)$ vs. those with an average weighing frequency of anything less than 7 days per week $(n=23)$.

To better characterize the weighing behaviors of the participants prior to starting WEIGH, we assessed weighing frequency over the previous 3 months via self-report using a single item: "Over the past 3 months, how often did you weigh yourself on average?" and included 7 response options: several times per day, one time per day, several times per week, one time per week, less than one time per week, less than one time per month, never weigh myself. These were then categorized into 3 categories: weighing daily, weighing weekly, or weighing less than weekly.

Weight control behaviors-Two questionnaires assessing weight control behaviors were administered at baseline and 6 months. The weight management strategies questionnaire (WMSQ) ${ }^{18}$ is a 37 -item questionnaire assessing utilization of eating and exercise behaviors that are associated with producing a caloric deficit for weight loss and typically discussed in weight loss trials ${ }^{19}$ Each item had 5 response options including never/ hardly ever, some of the time, about half of the time, much of the time, and always or almost always. In order to assess frequent engagement in these behaviors, which is suggestive of adoption, we dichotomized the items to examine those who engaged in these behaviors at 
least "much of the time." A total count of how many behaviors were engaged in was also calculated to assess overall adoption weight control behaviors. This questionnaire was used in previous trials assessing daily self-weighing for weight gain prevention, ${ }^{18,20}$ and has since been validated. ${ }^{21}$ These strategies were emphasized in the emailed lessons provided to all intervention participants.

The Eating Behavior Inventory (EBI) is a 26-item questionnaire assessing adoption of dietary weight control behaviors typically targeted in weight control programs and known to be associated with weight loss. ${ }^{22,23}$ The questionnaire includes both positive and negative behaviors, and negative behaviors are reverse scored. In contrast to the WMSQ, the EBI is a summary measure and the individual behaviors are scored to calculate a total score. An example of a positive behavior includes "I refuse food offered to me by others," and an example of a negative behavior includes, "I eat when I am not really hungry." Evidence indicates that EBI scores increase at the end of weight loss intervention and higher scores are associated with better weight loss outcomes. ${ }^{23}$ Total scores were calculated and participants missing more than one item were excluded (baseline: $n=1 ; 6$ months: $n=3$ ). Previous reliability estimates of the EBI suggest moderate-to-high reproducibility. ${ }^{22}$

Caloric intake and expenditure-At baseline and 6 months, caloric intake was measured via two 24-hour recalls using the Automated Self-Administered 24-Hour Dietary Recall (ASA-24) tool from the National Cancer Institute (NCI) ${ }^{24,25}$ Average caloric intake was calculated across the two days at each time point. At the same times, the Paffenbarger Exercise Habits Questionnaire was administered to capture weekly energy expenditure from leisure time physical activity. ${ }^{26,27}$

\section{Statistical Analysis}

Chi-square and Fisher exact tests and t-tests were conducted to compare differences in sociodemographic characteristics. Differences in the proportions of participants reporting high adoption (defined as at least "much of the time") of each of the individual weight control behaviors on the WMSQ by self-weighing frequency were examined using chisquare tests. For participants with missing data at 6 months, baseline values were imputed. Those missing both baseline and 6-months data were excluded $(n=1)$. Thus, the total $\mathrm{N}$ is 46 for the WMSQ questions. For the remaining outcomes, we conducted intent-to-treat analyses $(\mathrm{N}=47)$ using linear regression models to examine the effect of self weighing frequency on weight change, BMI change, percent weight loss, EBI total score change, caloric intake change, and caloric expenditure change at 6 months For all variables, baseline observation carried forward was used for missing values. Models were also analyzed adjusting for age, baseline BMI, and self-reported self-weighing frequency at baseline. All continuous variables were determined to meet assumptions of normality with the exception of caloric expenditure. A natural log transformation was applied to caloric expenditure to create a more normal distribution. Raw means are presented with statistical tests performed using the transformed data. Analyses were conducted using SPSS for Mac (Version 19, Chicago, IL). A cut-off value of alpha $<0.05$ was used to assess statistical significance. 


\section{Results}

\section{Self-weighing Frequency}

Overall compliance to self-weighing was high among intervention participants: $51 \%$ weighed every day; $76 \%$ weighed $\geq 6$ days per week, and $94 \%$ weighed $\geq 5$ days/week. The average self-weighing frequency among those weighing less than daily was 5.4 (SD: 1.2) days per week.

\section{Baseline Characteristics}

Table 1 highlights the baseline characteristics by self-weighing frequency of participants. On average, participants were 43 (SD: 11.4) years old, obese (BMI: 33.2 SD: $4.0 \mathrm{~kg} / \mathrm{m}^{2}$ ), female (70\%), White (77\%), and college-educated (77\%). At baseline, few participants were weighing daily; about half the sample (52\%) reported weighing less than weekly, 37\% reported weighing weekly, and $11 \%$ reported weighing daily over the 3 months before the study. Baseline characteristics did not differ by self-weighing frequency.

\section{Weight and BMI Change}

Weight loss over the study period was significantly greater among participants who weighed 7 days (daily weighers) compared to those who weighed less than 7 days per week (Figure 1). Daily weighers lost on average $9.2 \mathrm{~kg}$ (SD: 8.0) at 6 months compared to $3.1 \mathrm{~kg}$ (SD: 5.4) lost among those weighing less than daily (mean difference, $-6.1 \mathrm{~kg} ; 95 \% \mathrm{CI}-10.2$, $-2.1 ; \mathrm{p}=.004$ ). This equates to a percent weight loss of $9.4 \%$ (SD: 7.1) among daily weighers compared to $3.2 \%$ (SD: 5.3) among those who weighed less than daily (mean difference, $-6.2 \% ; 95 \% \mathrm{CI}-9.9,-2.5 ; \mathrm{p}=.002)$. We observed similar findings for absolute BMI change (mean difference, $-2.10 \mathrm{~kg} / \mathrm{m}^{2} ; 95 \% \mathrm{CI}-3.3,-0.7 ; \mathrm{p}=.004$ ).

\section{Weight Control Behaviors}

As shown in Table 2, participants who adhered to daily weighing throughout the intervention engaged more frequently in weight control behaviors associated with weight loss. Compared to those who weighed on average less than daily, a greater proportion of daily weighers reported reducing calorie intake by $500-1000$ calories per day (30\% vs. $11 \%$; $\mathrm{p}=.007$ ), reducing between meal snacks ( $37 \%$ vs. $17 \%$; $\mathrm{p}=.008$ ), reducing the number of times they ate out at restaurants other than fast food restaurants ( $30 \%$ vs. $13 \% ; \mathrm{p}=.02$ ), reducing frequency or portion sizes of desserts ( $41 \%$ vs. $20 \%$; $\mathrm{p}=.003)$, making one or two small changes to activity everyday ( $26 \%$ vs. $9 \%$; $\mathrm{p}=.01$ ), reducing the amount of time watching TV ( $23 \%$ vs. $7 \%$; $\mathrm{p}=.01$ ), exercising for a period of 30 minutes of more ( $41 \%$ vs. $20 \% ; \mathrm{p}=.003$ ), removing high calorie foods from home or office (39\% vs. $15 \% ; \mathrm{p}=.001$ ), and increasing daily steps (37\% vs. $20 \%$; $\mathrm{p}=.02$ ). We also observed that daily weighers adopted a greater number of total weight control behaviors on the WMSQ compared to those weighing less than daily (17.6 SD: 7.6 vs. 11.2 SD: 6.4; p=.004). For other dietary weight loss strategies, daily weighers reported on average higher EBI scores, lower calorie intake, and greater caloric expenditure compared to those who weighed anything less than daily (Table 3). These differences, however, did not reach statistical significance. Adjusted models produced similar results (data not shown). 


\section{Discussion}

Within the context of a daily self-weighing weight loss intervention, individuals who weighed everyday achieved clinically meaningful weight loss that was significantly greater than among those weighing less than daily. The likely reason for this difference is that daily weighers reported greater adoption of weight control behaviors compared to those who weighed less often. Even weighing 5 days per week, which was the average among the "non daily weighers," led to smaller weight losses, and promoted less utilization of behaviors known to be associated with weight loss. This suggests that daily weighing may trigger the self-regulatory processes that promote behavior change. This may be particularly true for those already primed to make changes to diet and exercise behaviors. Moreover, our findings suggest that weighing even most days of the week may not be enough for optimal self-regulation.

There is extensive evidence indicating that those who maintain high levels of adherence to self-monitoring of diet are physical activity are most successful with weight loss. ${ }^{6,28}$ However, in WEIGH, we discouraged participants from tracking diet and exercise behaviors because it is clear that this type of self-monitoring is difficult to sustain, ${ }^{6}$ even when using eHealth or mobile health approaches. ${ }^{29,30}$ Despite overall high adherence to daily weighing as the self-monitoring strategy, we observed a similar pattern with how adherence affects outcomes - those who were the most engaged achieved better outcomes. As is reflected in two of the questions asked on the behavioral strategies questionnaire, a small number of participants $(\mathrm{N}=9)$ reported recording the foods they had eaten or their physical activity $(\mathrm{N}=7)$. There were no differences by self-weighing frequency, suggesting that diet and exercise self-monitoring did not have a major impact on the effects of daily weighing on adoption of behavioral weight control strategies.

As has been shown previously, individuals receiving a weight loss program show improvements in adoption of diet and physical activity strategies associated with weight control. ${ }^{23}$ More robust mediation analyses have shown that dietary behaviors such as greater fruit and vegetable intake or those measured by the EBI mediate the effect of an eHealth weight loss intervention on weight outcomes. ${ }^{31,32}$ This isn't surprising because these programs are designed in such a way to facilitate these behavior changes. We found a similar uptake in adoption of these behaviors. However, despite all participants receiving the same information about making behavior change necessary to see weight loss, participants weighing daily reported higher utilization than those who weighed even 5 days per week. Despite this difference, there still may be utility in weighing most days of the week. Participants weighing less than daily weighed about 5 days per week and still saw clinically meaningful changes in weight and some positive changes in behavior. As such, recommendations for frequent weighing with an emphasis on daily being optimal are useful for overweight and obese individuals trying to lose weight.

Previous work examining differences in diet and exercise behaviors associated with selfweighing frequency has shown similar findings, albeit they were constrained by the limitations of cross-sectional study designs and self-reported self-weighing frequency. Linde and colleagues found that individuals who weighed at least weekly ate less fat and walked 
more blocks each day, compared to those weighing less than weekly. ${ }^{13}$ Another study found that adolescents who reported more frequent self-weighing ate less food, less calories, and followed more of a structured diet. ${ }^{14}$ Understanding the nuanced differences in selfweighing frequency warrants further examination by randomizing to varying self-weighing frequencies, but our findings suggest that weighing everyday may be necessary to achieve behavior change success when trying to lose weight.

A major strength of the study is our use of an objective weight measurement. Most studies have relied on self-report to compare daily to weekly weighing. As a result of the objective measurement, we were able to examine the differences between weighing daily and most days of the week and not just rely on self-reported categorized self-weighing measurement. To our knowledge, there have been no other studies that have had access to daily objective weighing data in this capacity. Gokee-Larose and colleagues examined an intervention that compared daily vs. weekly weighing and utilized a scale that stored weights. ${ }^{10}$ Although they found no differences between intervention groups, both groups received an intensive behavioral intervention and they did not examine patterns in self-weighing frequency and outcomes using the objective measure. One limitation of the scale with stored weights is that only 30 days of data, can be stored, perhaps preventing an examination of total days weighed and outcomes

Vanwormer and colleagues conducted a trial that similarly provided participants with a networked connected scale that sent weights via the phone line. ${ }^{33}$ They found similar results showing more frequent self-weighing led to greater weight loss. ${ }^{34}$ However, it is not clear whether there were differences among those who weighed daily compared to those who weigh less often. The present study adds to these findings by examining daily weighing vs. less frequent weighing and offers unique data on the underlying behavior changes that are perhaps facilitated by daily weighing

\section{Limitations}

Although our findings suggest the utility of weighing everyday for greater weight loss and adoption of weight control behaviors, there are several limitations worth mentioning. First, our sample size was small and it is possible that we did not have enough power to evaluate the secondary outcomes of EBI score, caloric intake, and caloric expenditure or adjust for all possible confounders. We did not have a randomized comparison of daily weighing vs. less than daily weighing and it is possible that self-weighing frequency may be a proxy for adherence to the intervention overall. Even with that limitation, it is interesting that among those who weighed 5 days per week, the average among those weighing less than daily, we found significantly smaller weight losses and less frequent engagement with weight control behaviors. Although, those weighing 5 days still produced clinically meaningful weight loss outcomes. As such, the limited variability in self-weighing frequency does not allow us to examine whether weighing less than 5 days per week (e.g., weekly, less than weekly) produces smaller weight losses and fewer behavioral changes compared to weighing 5 days. Future research examining greater variability in self-weighing frequency or randomizing by weighing frequency is warranted. Lastly, we examined weight control strategies by individual items on the questionnaire. It is possible that multiple analyses may increase the 
odds of spurious findings. Finally, our sample was predominantly female, white, and college-educated. As such, it is not possible for us to infer whether similar findings would be found with a different population.

\title{
Conclusions
}

Daily weighing was associated with greater weight loss than weighing most days of the week. This difference is likely because those who weigh daily also report greater adoption of diet and exercise behaviors associated with weight control. The utility of daily weighing is becoming more widely adopted in the obesity research field and our findings provide further data to encourage prescribing daily weighing as the optimal self-weighing frequency.

\section{Acknowledgements}

\author{
The authors have no acknowledgements. \\ Funding Disclosure: \\ The authors thank the Lineberger Comprehensive Cancer Center, Cancer Control Education Program Fellowship \\ (\#R25 CA057726) for providing funding for the WEIGH study.
}

\section{References}

1. Ogden CL, Carroll MD, Kit BK, Flegal KM. Prevalence of childhood and adult obesity in the United States, 2011-2012. JAMA. 2014; 311(8):806-814. [PubMed: 24570244]

2. Field AE, Coakley EH, Must A, et al. Impact of overweight on the risk of developing common chronic diseases during a 10-year period. Arch Internal Med. 2001; 161(13):1581. [PubMed: 11434789]

3. Wolin KY, Carson K, Colditz GA. Obesity and Cancer. The oncologist. 2010; 15(6):556. [PubMed: 20507889]

4. Jensen MD, Ryan DH, Apovian CM, et al. 2013 AHA/ACC/TOS Guideline for the Management of Overweight and Obesity in Adults: A Report of the American College of Cardiology/American Heart Association Task Force on Practice Guidelines and The Obesity Society. Circulation. 2013

5. Baker RC, Kirschenbaum DS. Self-monitoring may be necessary for successful weight control. Behav Ther. 1993; 24(3):377-394.

6. Burke LE, Wang J, Sevick MA. Self-monitoring in weight loss: a systematic review of the literature. J Am Diet Assoc. 2011; 111(1):92-102. [PubMed: 21185970]

7. Kanfer FH, Karoly P. Self-control: A behavioristic excursion into the lion's den. Behav Ther. 1972; 3(3):389-416.

8. Boutelle K. Weighing the evidence: benefits of regular weight monitoring for weight control. J Nutr Educ Behav. 2006; 38(3):131. [PubMed: 16731444]

9. Steinberg DM, Tate DF, Bennett GG, Ennett S, Samuel-Hodge C, Ward DS. The efficacy of a daily self-weighing weight loss intervention using smart scales and email. Obesity. 2013; 21(9):17891797. [PubMed: 23512320]

10. Gokee-Larose J, Gorin AA, Wing RR. Behavioral self-regulation for weight loss in young adults: a randomized controlled trial. Int J Behav Nutr Phys Act. 2009; 6:10. [PubMed: 19220909]

11. Linde JA, Jeffery RW, French SA, Pronk NP, Boyle RG. Self-weighing in weight gain prevention and weight loss trials. Ann Behav Med. 2005; 30(3):210-216. [PubMed: 16336072]

12. Vanwormer JJ, French SA, Pereira MA, Welsh EM. The impact of regular self-weighing on weight management: a systematic literature review. Int J Behav Nutr Phys Act. 2008; 5:54. [PubMed: 18983667] 
13. Linde JA, Utter J, Jeffery RW, Sherwood NE, Pronk NP, Boyle RG. Specific food intake, fat and fiber intake, and behavioral correlates of BMI among overweight and obese members of a managed care organization. Int J Behav Nutr Phys Act. 2006; 3:42. [PubMed: 17125525]

14. Alm ME, Neumark-Sztainer D, Story M, Boutelle KN. Self-Weighing and Weight Control Behaviors Among Adolescents with a History of Overweight. J Adolescent Health. 2009; 44(5): 424-430.

15. Knowler WC, Barrett-Connor E, Fowler SE, et al. Reduction in the incidence of type 2 diabetes with lifestyle intervention or metformin. N Engl J Med. 2002; 346(6):393-403. [PubMed: 11832527]

16. Tate DF, Jackvony EH, Wing RR. Effects of Internet behavioral counseling on weight loss in adults at risk for type 2 diabetes: a randomized trial. JAMA. 2003; 289(14):1833-1836. [PubMed: 12684363]

17. Tate DF, Jackvony EH, Wing RR. A randomized trial comparing human e-mail counseling, computer-automated tailored counseling, and no counseling in an Internet weight loss program. Arch Int Med. 2006; 166(15):1620. [PubMed: 16908795]

18. Wing RR, Tate D, Espeland M, et al. Weight gain prevention in young adults: design of the study of novel approaches to weight gain prevention (SNAP) randomized controlled trial. BMC Public Health. 2013; 13(1):300. [PubMed: 23556505]

19. Brownell, K. The LEARN program for weight management. Dallas, TX: American Health Publishing Company; 2004.

20. Gokee LaRose J, Tate DF, Gorin AA, Wing RR. Preventing weight gain in young adults: a randomized controlled pilot study. Am J Prev Med. 2010; 39(1):63-68. [PubMed: 20537843]

21. Pinto AM, Fava JL, Raynor HA, LaRose JG, Wing RR. Development and validation of the weight control strategies scale. Obesity. 2013; 21(12):2429-2436. [PubMed: 23512914]

22. O'Neil PM, Currey HS, Hirsch AA, et al. Development and Validation of the Eating Behavior Inventory. Journal of Psychopatho Behav. 1979; 1(2):123-132.

23. O'Neil PM, Rieder S. Utility and validity of the Eating Behavior Inventory in clinical obesity research: a review of the literature. Obes Rev. 2005; 6(3):209-216. [PubMed: 16045636]

24. Subar AF, Thompson FE, Potischman N, et al. Formative research of a quick list for an automated self-administered 24-hour dietary recall. J Am Diet Assoc. 2007; 107(6):1002-1007. [PubMed: 17524721]

25. Kirkpatrick SI, Subar AF, Douglass D, et al. Performance of the Automated Self-Administered 24hour Recall relative to a measure of true intakes and to an interviewer-administered 24-h recall. Am J Clin Nutr. 2014

26. Paffenbarger RS Jr, Wing AL, Hyde RT. Physical activity as an index of heart attack risk in college alumni. Am J Epidemiol. 1995; 142(9):889. [PubMed: 7572969]

27. Ainsworth B, Leon AS, Richardson D, Jacobs DR. Paffenbarger. Accuracy of the College Alumnus Physical Activity Questionnaire. J Clin Epidemiol. 1993; 46:1403-1411. [PubMed: 8263567]

28. Sarwer DB, von Sydow Green A, Vetter ML, Wadden TA. Behavior therapy for obesity: where are we now? Curr Opin Endocrinol Diabetes Obes. 2009; 16(5):347. [PubMed: 19623061]

29. Burke LE, Styn MA, Sereika SM, et al. Using mHealth Technology to Enhance Self-Monitoring for Weight Loss: A Randomized Trial. Am J Prev Med. 2012; 43(1):20-26. [PubMed: 22704741]

30. Steinberg DM, Levine EL, Askew S, Foley P, Bennett GG. Daily text messaging for weight control among racial and ethnic minority women: randomized controlled pilot study. J Med Internet Res. 2013; 15(11):e244. [PubMed: 24246427]

31. Norman GJ, Kolodziejczyk JK, Adams MA, Patrick K, Marshall SJ. Fruit and vegetable intake and eating behaviors mediate the effect of a randomized text-message based weight loss program. Prev Med. 2013; 56(1):3-7. [PubMed: 23085329]

32. Ambeba EJ, Ye L, Sereika SM, et al. The Use of mHealth to Deliver Tailored Messages Reduces Reported Energy and Fat Intake. J Cardiovasc Nurs. 2014

33. VanWormer JJ, Martinez AM, Benson GA, et al. Telephone counseling and home telemonitoring: the Weigh by Day Trial. Am J Health Behav. 2009; 33(4):445-454. [PubMed: 19182989] 
34. VanWormer JJ, Martinez AM, Martinson BC, et al. Self-Weighing Promotes Weight Loss for Obese Adults. Am J Prev Med. 2009; 36(1):70-73. [PubMed: 18976879] 


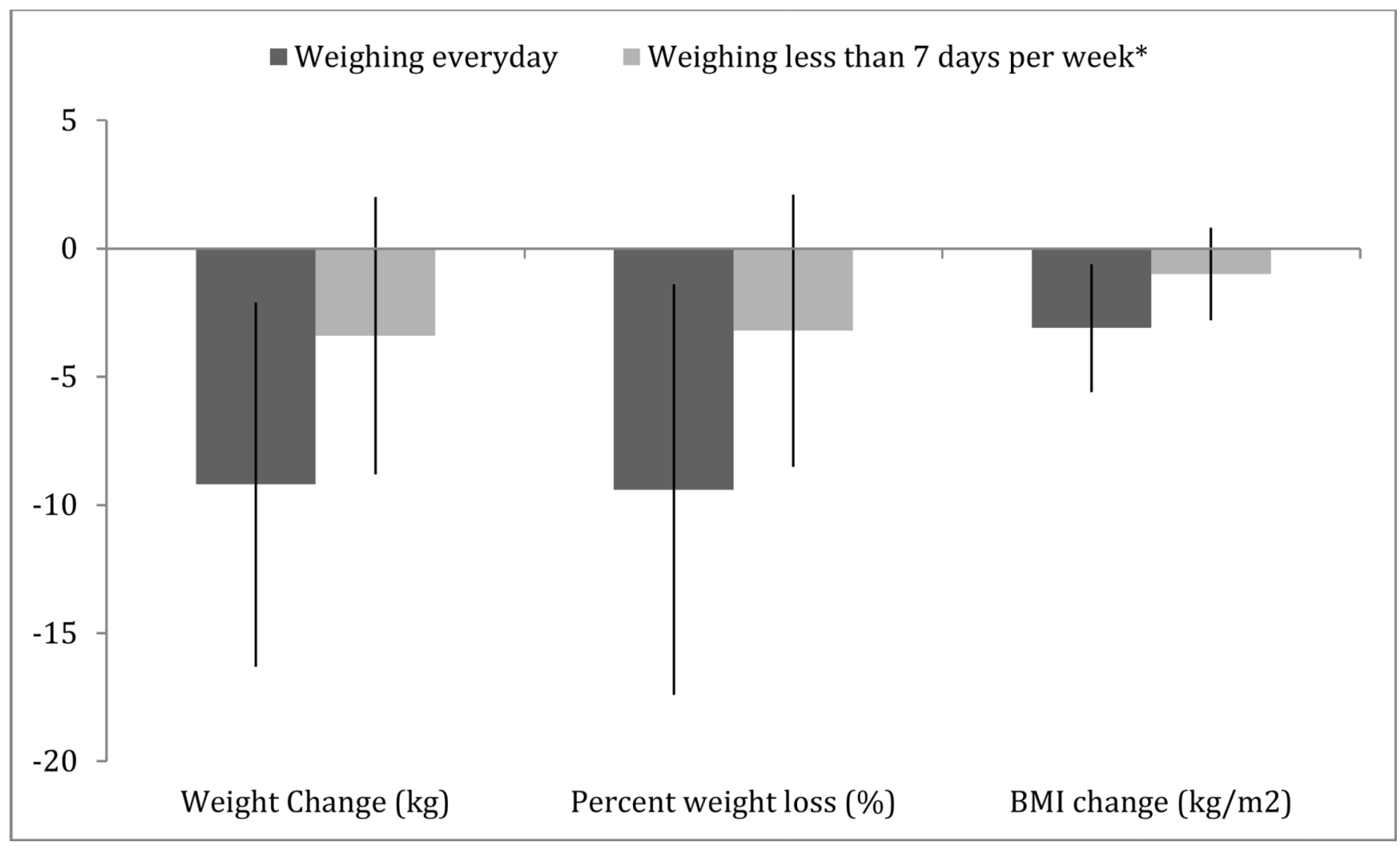

Figure 1.

Anthropometric changes by self-weighing frequency among intervention participants $(\mathrm{n}=47)$ enrolled in the WEIGH study, 2011. Means (SD) reported.

*Average self-weighing frequency in this group was 5.4, (SD: 1.2) days per week 
Table 1

Baseline characteristics by self-weighing frequency of intervention participants in the WEIGH Study, 2011 $(n=47)$

\begin{tabular}{|l|c|c|r|}
\hline & $\begin{array}{c}\text { Weighing everyday } \\
(\mathbf{n = 2 4 )}\end{array}$ & $\begin{array}{c}\text { Weighing less than 7 } \\
\text { days per week (n=23) }\end{array}$ & p-value \\
\hline Age in years, Mean (SD) & $44.4(11.0)$ & $41.3(11.8)$ & 0.33 \\
\hline Sex, N (\%) & & & 0.59 \\
\hline Male & $8(33)$ & $6(26)$ & \\
\hline Female & $16(67)$ & $17(74)$ & \\
\hline Race/ethnicity, N (\%) & & & 0.91 \\
\hline Black & $3(13)$ & $3(13)$ & \\
\hline White & $18(75)$ & $18(78)$ & \\
\hline Other & $3(13)$ & $2(9)$ & \\
\hline Education, N (\%) & & & 0.36 \\
\hline High School, Vocational, or Some College & $9(38)$ & $2(9)$ & \\
\hline College Graduate or Greater & $15(62)$ & $21(91)$ & \\
\hline Weight (kg), Mean (SD) & $95.3(18.5)$ & $93.6(12.8)$ & 0.72 \\
\hline BMI (kg/m2), Mean (SD) & $33.4(4.4)$ & $33.0(3.6)$ & 0.75 \\
\hline Self-weighing Frequency, N (\%) & & & 0.84 \\
\hline Daily & $3(13)$ & $2(9)$ & \\
\hline Weekly & $8(33)$ & $9(41)$ & \\
\hline Less than one time/week & $13(54)$ & $11(50)$ & \\
\hline
\end{tabular}

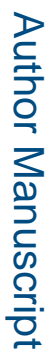




\section{Table 2}

Engagement in weight loss strategies measured by the Weight Management Strategies Questionnaire at 6 months by self-weighing frequency among intervention participants in the WEIGH study, $2011(\mathrm{n}=46)^{*}$

\begin{tabular}{|c|c|c|c|}
\hline Weight Control Strategies & $\begin{array}{l}\text { Weighing everyday } \\
(\mathbf{n}=\mathbf{2 3})\end{array}$ & $\begin{array}{c}\text { Weighing less } \\
\text { than } 7 \text { days } \\
(n=23)\end{array}$ & \multirow{3}{*}{$\begin{array}{c}\text { P-value } \\
0.007\end{array}$} \\
\hline & \multicolumn{2}{|c|}{ Number $(\%)$} & \\
\hline Reduced caloric intake by $500-1000$ calories per day & $14(30 \%)$ & $5(11 \%)$ & \\
\hline Cut out/reduced sweets or junk food & $17(37 \%)$ & $11(24 \%)$ & 0.07 \\
\hline Cut out/reduced between meal snacks & $17(37 \%)$ & $8(17 \%)$ & 0.008 \\
\hline Cut out/reduced late night snacking & $21(46 \%)$ & $17(37 \%)$ & 0.12 \\
\hline Ate less meat & $10(22 \%)$ & $8(17 \%)$ & 0.55 \\
\hline Ate less carbohydrates & $11(24 \%)$ & $8(17 \%)$ & 0.37 \\
\hline Ate less fat & $14(30 \%)$ & $11(24 \%)$ & 0.38 \\
\hline Reduced portion sizes & $14(30 \%)$ & $10(22 \%)$ & 0.24 \\
\hline Decreased number of times ate out at fast food restaurants & $18(39 \%)$ & $13(28 \%)$ & 0.12 \\
\hline Decreased number of times that ate out at other restaurants & $14(30 \%)$ & $6(13 \%)$ & 0.02 \\
\hline Changed food preparation techniques & $10(22 \%)$ & $6(14 \%)$ & 0.22 \\
\hline Drank less alcohol or changed type of alcoholic drink to reduce calories & $12(26 \%)$ & $11(24 \%)$ & 0.77 \\
\hline Drank less fruit juice or fruit drinks (e.g., $100 \%$ fruit juice, fruit punch, lemonade) & $16(35 \%)$ & $12(26 \%)$ & 0.23 \\
\hline Drank less high calorie coffee drinks (e.g., caramel macchiato, cafe mocha) & $15(33 \%)$ & $17(37 \%)$ & 0.52 \\
\hline Increased fruit and vegetable consumption & $17(37 \%)$ & $12(26 \%)$ & 0.13 \\
\hline Increased water consumption & $17(37 \%)$ & $14(30 \%)$ & 0.35 \\
\hline Used frozen entrees such as Lean Cuisine or Smart Ones & $9(20 \%)$ & $6(13 \%)$ & 0.35 \\
\hline Used liquid meal replacements such as Slim Fast & $0(0 \%)$ & $0(0 \%)$ & 1.0 \\
\hline $\begin{array}{l}\text { Followed a structured meal plan that limited choices for breakfast, lunch, and dinner } \\
\text { (e.g., nutrisystem meals) }\end{array}$ & $4(9 \%)$ & $2(4 \%)$ & 0.67 \\
\hline Used meal replacement bars such as Power Bars or Zone bars & $1(2 \%)$ & $1(2 \%)$ & 1.0 \\
\hline Decreased frequency or portion sizes of desserts & $19(41 \%)$ & $9(20 \%)$ & 0.003 \\
\hline Skipped meals & $1(2 \%)$ & $3(7 \%)$ & 0.61 \\
\hline Made one or two small changes to activity every day & $12(26 \%)$ & $4(9 \%)$ & 0.01 \\
\hline Used the stairs instead of the elevator & $16(35 \%)$ & $10(22 \%)$ & 0.07 \\
\hline Wore a pedometer & $3(7 \%)$ & $1(2 \%)$ & 0.61 \\
\hline Reduced the amount of time watching $\mathrm{TV}$ & $11(24 \%)$ & $3(7 \%)$ & 0.01 \\
\hline Used home exercise equipment & $3(7 \%)$ & $2(4 \%)$ & 1.0 \\
\hline Exercised at a gym or participated in an exercise class & $9(20 \%)$ & $8(17 \%)$ & 0.76 \\
\hline Exercised with a personal trainer & $0(0 \%)$ & $1(2 \%)$ & 1.0 \\
\hline Exercised for a period of 30 minutes or more & $19(41 \%)$ & $9(20 \%)$ & 0.003 \\
\hline Recorded or graphed physical activity & $5(11 \%)$ & $2(4 \%)$ & 0.41 \\
\hline Recorded or wrote down the type and quantity of food eaten & $6(13 \%)$ & $3(7 \%)$ & 0.46 \\
\hline Removed high calorie foods (e.g., cakes, cookies, or candy) from home or office & $18(39 \%)$ & $7(15 \%)$ & 0.001 \\
\hline
\end{tabular}




\begin{tabular}{|l|c|c|c|}
\hline Weight Control Strategies & $\begin{array}{c}\text { Weighing everyday } \\
(\mathbf{n = 2 3})\end{array}$ & $\begin{array}{c}\text { Weighing less } \\
\text { than 7 days } \\
(\mathbf{n}=\mathbf{2 3})\end{array}$ & P-value \\
\hline & \multicolumn{2}{|c|}{ Number (\%) } & \\
\hline $\begin{array}{l}\text { Attended or participated in a structured weight loss group or program (e.g., Weight } \\
\text { Watchers, Jenny Craig) }\end{array}$ & $2(4 \%)$ & $1(2 \%)$ & 1.0 \\
\hline Followed a specific weight loss diet (e.g. Atkins, South Beach Diet) & $0(0 \%)$ & $0(0 \%)$ & 1.0 \\
\hline Made one or two small changes to your diet every day & $12(26 \%)$ & $7(15 \%)$ & 0.13 \\
\hline Increased daily steps & $17(37 \%)$ & $9(20 \%)$ & $\mathbf{0 . 0 2}$ \\
\hline
\end{tabular}

N $=46$ because one participant did not complete the WMSQ at baseline. 
Table 3

Changes in diet and physical activity behaviors at 6 months by self-weighing frequency among participants in the WEIGH Study, $2011(\mathrm{n}=47)$

\begin{tabular}{|c|c|c|c|}
\hline & $\begin{array}{c}\text { Weighing everyday } \\
\text { Mean (SD) } \\
(\mathbf{n}=\mathbf{2 4})\end{array}$ & $\begin{array}{l}\text { Weighing less than } 7 \text { days } \\
\text { Mean (SD) } \\
(\mathbf{n = 2 3})\end{array}$ & p-value \\
\hline \multicolumn{4}{|l|}{ EBI Total Score ${ }^{*}$} \\
\hline Baseline & $75.1(10.7)$ & $70.3(10.4)$ & \\
\hline End Point & $91.1(13.0)$ & $81.7(9.3)$ & \\
\hline Change, $95 \%(\mathrm{CI})$ & $14.8(8.8,20.7)$ & $11.4(8.1,14.7)$ & 0.32 \\
\hline \multicolumn{4}{|l|}{ Caloric Intake } \\
\hline Baseline & $2014.1(492.4)$ & $2013.6(688.6)$ & \\
\hline End Point & 1413.5 (479.7) & $1660.5(731.9)$ & \\
\hline Change, $95 \%(\mathrm{CI})$ & $-600.6(-876.5,-324.7)$ & $-353.1(-590.3,-116.0)$ & 0.17 \\
\hline \multicolumn{4}{|c|}{ Caloric Expenditure $^{* *}$} \\
\hline Baseline & $1038.8(1178.1)$ & $601.5(645.4)$ & \\
\hline End Point & $1264.6(1140.5)$ & $811.1(1351.1)$ & \\
\hline Change, $95 \%(\mathrm{CI})$ & $+225.7(-250.9,702.4)$ & $+209(-410.4,829.7)$ & 0.23 \\
\hline
\end{tabular}

